\title{
Automaticity and cognitive control: Effects of cognitive load on cue-controlled reward choice
}

\author{
Seabrooke, T
}

http://hdl.handle.net/10026.1/12011

\section{$10.1177 / 1747021818797052$}

Quarterly Journal of Experimental Psychology

SAGE Publications

All content in PEARL is protected by copyright law. Author manuscripts are made available in accordance with publisher policies. Please cite only the published version using the details provided on the item record or document. In the absence of an open licence (e.g. Creative Commons), permissions for further reuse of content should be sought from the publisher or author. 


\section{Automaticity and cognitive control: Effects of cognitive load on cue-controlled reward choice}

\begin{tabular}{|r|l|}
\hline Journal: & Quarterly Journal of Experimental Psychology \\
\hline Manuscript ID & QJE-STD-18-105.R1 \\
\hline Manuscript Type: & Standard Article \\
\hline Complete List of Authors: & $\begin{array}{l}\text { Seabrooke, Tina; Plymouth University, } \\
\text { Wills, Andy; Plymouth University, } \\
\text { Hogarth, Lee; University of Exeter } \\
\text { Mitchell, Chris; Plymouth University }\end{array}$ \\
\hline Keywords: & $\begin{array}{l}\text { outcome-response priming, automaticity, cognitive control, outcome } \\
\text { devaluation }\end{array}$ \\
\hline
\end{tabular}

\section{SCHOLARONE \\ Manuscripts}


1

2

3

4

5

6

7

8

9

10

11

12

13

14

15

16

17

18

19

\section{Automaticity and cognitive control: Effects of cognitive load on cue-controlled reward choice}

Tina Seabrooke ${ }^{1}$, Andy J. Wills ${ }^{1}$, Lee Hogarth ${ }^{2}$ \& Chris J. Mitchell ${ }^{1}$

${ }^{2}$ University of Exeter, UK

Running head: Automatic and controlled cue-control

Please address correspondence to:

Dr Tina Seabrooke

School of Psychology

Plymouth University

Devon

PL4 8AA

United Kingdom

Email: tina.seabrooke@plymouth.ac.uk 


\begin{abstract}
The extent to which human outcome-response (O-R) priming effects are automatic or under cognitive control is currently unclear. Two experiments tested the effect of cognitive load on O-R priming to shed further light on the debate. In Experiment 1, two instrumental responses earned beer and chocolate points in an instrumental training phase. Instrumental response choice was then tested in the presence of beer, chocolate and neutral stimuli. On test, a Reversal instruction group were told that the stimuli signalled which response would not be rewarded. The transfer test was also conducted under either minimal (No Load) or considerable (Load) cognitive load. The NonReversal groups showed O-R priming effects, where the reward cues increased the instrumental responses that had previously produced those outcomes, relative to the neutral stimulus. This effect was observed even under cognitive load. The Reversal No Load group demonstrated a reversed effect, where response choice was biased towards the response that was most likely to be rewarded according to the instruction. Most importantly, response choice was at chance in the Reversal Load condition. In Experiment 2, cognitive load abolished the sensitivity to outcome devaluation that was otherwise seen when multiple outcomes and responses were cued on test. Collectively, the results demonstrate that complex O-R priming effects are sensitive to cognitive load, while the very simple, standard O-R priming effect is more robust.
\end{abstract}

Keywords: outcome-response priming; automaticity; cognitive control; outcome devaluation 
Reward-predictive Pavlovian conditioned stimuli (CSs) are powerful cues that can guide and invigorate instrumental reward-seeking behaviours (e.g., Hogarth, Dickinson, \& Duka, 2010; Lovibond, 1981). This interaction between Pavlovian and instrumental learning is often adaptive because it allows animals to selectively seek food rewards that are predictable in their environment. Such cue reactivity is also thought to promote harmful behaviours in some cases, though, such as drug-seeking (Hogarth, Balleine, Corbit, \& Killcross, 2013), gambling (Wulfert, Maxson, \& Jardin, 2009), and overeating (Ridley-Siegert, Crombag, \& Yeomans, 2015; van Steenbergen, Watson, Wiers, Hommel, \& de Wit, 2017). In these latter cases, reward-related cues might undermine long-term goals of abstinence by precipitating relapse. Pavlovian-instrumental interactions are often thought to be relatively automatic effects, because cue reactivity can be seen despite explicit contradictory goals and desires (e.g., Watson, de Wit, Hommel, \& Wiers, 2012). The current paper aims to explore the conditions under which reward-predictive cues bias instrumental actions in an automatic (versus controlled) fashion.

Outcome-selective Pavlovian-instrumental transfer (PIT) tasks are often used to assess the influence of Pavlovian CSs on instrumental actions (Colwill \& Rescorla, 1988; Estes, 1943; Hogarth, Dickinson, Wright, Kouvaraki, \& Duka, 2007; Kruse, Overmier, Konz, \& Rokke, 1983; Lovibond, 1981; Walker, 1942). The traditional PIT procedure, developed in rodent studies, involves separate Pavlovian and instrumental training procedures (the order of which varies), followed by a final transfer test. During Pavlovian conditioning, two Pavlovian CSs (stimuli S1 and S2) are trained to predict different rewarding outcomes (O1 and O2), such that stimulus S1 earns outcome $\mathrm{O} 1$ and S2 earns $\mathrm{O} 2$ (S1-01, S2-O2). In a separate instrumental training phase, rats also learn to perform two instrumental responses (R1 and R2) to earn outcome each (R1-O1, R2-O2). In the final transfer test, either instrumental response choice (R1 versus R2) or the absolute rate of each response is tested in extinction in the presence of each Pavlovian stimulus, relative to a neutral stimulus or a baseline period. The classic result is that each Pavlovian CS selectively potentiates the instrumental response that predicts the same outcome (e.g., Colwill \& Rescorla, 1988; Corbit \& Balleine, 2005; Hogarth et 
al., 2007). That is, stimulus S1 increases choice of R1 more than R2, and S2 increases choice of R2 more than R1. In humans, a highly related phenomenon can be seen when pictorial reward cues (i.e., pictures of the rewards) are used in place of Pavlovian CSs that were established during the experiment (e.g., Hogarth \& Chase, 2011; Martinovic et al., 2014; Pritchard, Weidemann, \& Hogarth, 2017; Seabrooke, Hogarth, \& Mitchell, 2016). These effects are often referred to as "PIT" effects, since it is widely assumed that pictorial reward cues are associated with rewards precisely because they have undergone Pavlovian conditioning outside the laboratory (Hogarth, 2012; Hogarth \& Chase, 2011; Martinovic et al., 2014; Watson, Wiers, Hommel, Ridderinkhof, \& de Wit, 2016). However, it might be argued that there is some fundamental difference between Pavlovian CSs that are established inside and outside of the laboratory. We therefore retain a distinction between these two effects for the present purposes. Thus, we refer to effects obtained using the traditional PIT procedure (where the Pavlovian associations are established during the experiment itself) as "PIT effects", and effects obtained using non-arbitrary reward cues as "outcome-response (O-R) priming" effects (following Watson, Wiers, Hommel, Gerdes, \& de Wit, 2017, and Watson, Wiers, Hommel, Ridderinkhof, \& de Wit, 2016).

The current experiments focus on the mechanisms that underlie O-R priming effects. In the past, these mechanisms have been hotly debated (Cartoni, Moretta, Puglisi-Allegra, Cabib, \& Baldassarre, 2015; Cohen-Hatton, Haddon, George, \& Honey, 2013; de Wit \& Dickinson, 2009; Hardy, Mitchell, Seabrooke, \& Hogarth, 2017; Hogarth et al., 2014; Seabrooke, Le Pelley, Hogarth, \& Mitchell, 2017). O-R priming effects are usually regarded as relatively automatic effects, primarily because they are often insensitive to outcome devaluation manipulations (Hogarth, 2012; Hogarth \& Chase, 2011, but also see Seabrooke et al., 2017). Very similar effects have been observed with traditional PIT procedures (Colwill \& Rescorla, 1990; Corbit, Janak, \& Balleine, 2007; van Steenbergen et al., 2017; Watson, Wiers, Hommel, \& de Wit, 2014, but also see Allman, DeLeon, Cataldo, Holland, \& Johnson, 2010; Eder \& Dignath, 2016a, 2016b). Hogarth and Chase (2011), for example, trained smokers to perform two responses to earn tobacco and chocolate points. Either 
tobacco or chocolate was then devalued by presenting health warnings about the outcome, before response choice was tested in the presence of tobacco, chocolate and neutral stimuli. On test, overall response choice was biased towards the valued outcome; participants tended to choose the response that predicted the valued outcome. The tobacco and chocolate stimuli also selectively increased the responses that predicted those outcomes, relative to the neutral stimulus. Most importantly, the size of the O-R priming effect for the valued and devalued outcome did not significantly differ in size. The effect was therefore considered to be insensitive to the devaluation manipulation. Insensitivity to devaluation is regarded as the gold-standard test of automatic or habitual control (Dickinson, 1985). Both O-R priming effects and PIT effects are, therefore, usually thought to be relatively automatic. In particular, the Pavlovian cues are often suggested to activate the sensory properties (and, importantly, not the current incentive value) of the outcome, which then automatically trigger the associated instrumental response (e.g., Alarcón \& Bonardi, 2016; Hogarth \& Chase, 2011; Watson et al., 2014).

Although the insensitivity described above points to an automatic mechanism, other data speak against a truly automatic mechanism. Hogarth et al. (2014), for example, reported an attenuated O-R priming effect in participants who were instructed that the stimuli did not signal which response would be rewarded during the transfer test. In another study, instructions stating that the pictures signalled which response would not be rewarded similarly produced a completely reversed effect (Seabrooke et al., 2016). This sensitivity to post-training verbal instructions suggests that O-R priming effects might not reflect an automatic process, but rather a controlled reasoning process (Hardy et al., 2017; Hogarth et al., 2014; Mitchell, De Houwer, \& Lovibond, 2009; Seabrooke et al., 2016, 2017).

So on the one hand we have several demonstrations of O-R priming effects that were insensitive to outcome devaluation manipulations, which points to an automatic mechanism. On the other hand, O-R priming effects are sensitive to instructional manipulations, which suggests a 
controlled process. Of course, instructional effects do not necessarily preclude an underlying automatic process; a controlled process might be superimposed on top of an automatic process (e.g., McLaren et al., 2014, 2018) $)^{1}$. Indeed, instructional manipulations might even promote a controlled process, effectively suppressing an automatic process that is potentially responsible for the original (non-instructed) effect. One way to test for an automatic process that is concealed by a controlled process - the approach taken in the current experiments - is to use a secondary task that requires the controlled process. Cognitive load tasks, for example, are recognised as an effective way to exhaust controlled processing capacity and thereby increase the potential to detect underlying automaticity (De Houwer \& Beckers, 2003; de Wit, Ridderinkhof, Fletcher, \& Dickinson, 2013; Le Pelley, Oakeshott, \& McLaren, 2005; Wills, Graham, Koh, McLaren, \& Rolland, 2011).

The present experiments sought evidence of an "automatic" O-R priming effect, when a controlled process was less likely to determine response choice. We therefore took two examples of O-R priming effects that appear to be under cognitive control and applied cognitive load to test for underlying automaticity. Experiment 1 first examined whether a typical O-R priming effect survives a cognitive load task. We also tested whether Seabrooke et al.'s (2016) reversal instruction procedure would reveal evidence of automaticity under load. Similarly, Experiment 2 tested the effect of cognitive load on Seabrooke et al.'s (2017) more complex O-R priming effect. This effect, which was obtained by cueing high- and low-value outcomes together on test, was highly sensitive to a devaluation manipulation. Experiment 2 tested whether this O-R priming effect would become insensitive to devaluation under cognitive load. Both experiments used Wills et al.'s (2011) cognitive load task, in which participants were required to remember number sequences during the transfer test. Hence, working memory was occupied at the point when responses were being made. We

\footnotetext{
${ }^{1}$ It is not obvious, however, how the dual-process account would explain why O-R priming effects are often both insensitive to devaluation and sensitive to instructional manipulations under very similar circumstances.
} 
chose this task because it successfully generated a switch from rule-based to feature-based generalisation in a causal learning task (Wills et al., 2011).

\section{Experiment 1}

Experiment 1 was based on Seabrooke et al.'s (2016) reversal instruction experiment. Participants were randomly allocated to an instruction (Non-Reversal or Reversal) and cognitive load (No Load or Load) group at the start of the experiment. All participants first completed an instrumental training phase, where two responses were trained to predict beer and chocolate points. Instrumental response choice was then tested in the presence of beer, chocolate and neutral stimuli. The Reversal instruction groups viewed the statement "Pictures signal which response will NOT be rewarded!" throughout the transfer test. We used this instruction to be consisted with our previous work (Seabrooke et al., 2016), where we observed very strong reversal effects. The Load groups also completed a cognitive load task (described below) during the transfer test.

We anticipated an O-R priming effect in the Non-Reversal No Load group. That is, we expected the beer and chocolate stimuli to selectively increase the responses that predicted those outcomes. We also expected the opposite effect in the Reversal No Load group. The questions were with respect to the Load groups. If the Non-Reversal Load group demonstrate an O-R priming effect, it would suggest that such effects are, at least partly, automatic. Moreover, if the reversed priming effect gives way to a standard priming effect in the Reversal Load condition, it would provide especially compelling evidence of automaticity.

\section{Method}

Participants. Sixty-one participants (31 males, aged between 18 and 27, $M=20.23$ years, $S E M=0.25$ years) were recruited from Plymouth University for course credit or on a voluntary basis. There were an equal number of men and women in each group, except in the Reversal Load group, where there were nine males and eight females. The participants were recruited through convenience sampling, and we attempted to ensure that there were at least as many participants 
per group as in Seabrooke et al.'s (2016) Experiment 2, where we saw a strong reversed O-R priming effect. Potential participants were encouraged to take part if they liked beer and chocolate. We did not measure whether the participants were currently dieting or not. The experiment was approved by the Plymouth University Ethics Committee.

Apparatus and materials. The experiment was programmed in E-Prime 2.0 (Psychology Software Tools, Inc; pstnet.com) and was presented on a 22-inch computer monitor in a quiet testing room. Stimuli were presented on a white background, and responses were made using a standard keyboard. The pictorial chocolate stimulus was a close-up of Cadbury's chocolate chunks, the beer stimulus depicted two glasses of beer knocking together, and the neutral stimulus was a grey rectangle. Headphones were worn throughout the experiment. A $330 \mathrm{ml}$ bottle of Beck's beer and a 45 gram Cadbury's Dairy Milk chocolate bar served as props.

Overview. The experiment was run on weekdays from 9am to $5 \mathrm{pm}$, and took approximately 30 minutes per participant to complete. The participants were not restricted from eating or drinking before the experiment. After providing informed consent, the participants were shown the beer and chocolate props and were told that they could try to win points towards those rewards. The participants then completed a practice phase of the cognitive load task, to prepare for the transfer test. Two instrumental responses were then trained to earn beer and chocolate points, before instrumental contingency knowledge was assessed. Response choice was finally tested in the presence of beer, chocolate and neutral stimuli. All groups completed each stage of the experiment.

Practice cognitive load task. There were 10 practice cognitive load trials. Each trial began with a blank screen $(500 \mathrm{~ms})$, before six unique, randomly chosen (without replacement), single-digit numbers sounded through the participants' headphones. The numbers were presented at $330 \mathrm{~ms}$ intervals and were voice-synthesized. The number sequence was followed by a centrally-presented fixation cross (500ms), and then a blank screen (500ms). Either the letter " $C$ " or " $M$ " was then presented until participants pressed the corresponding key on the keyboard. Finally, a number from 
the first five numbers of the earlier auditory sequence was presented on-screen, and participants were told to select the number that came next in the sequence. For example, if participants initially heard the numbers, " $3,4,6,1,5,2$ " and the number " 6 " was then presented, the correct answer would be " 1 ". Responding was not time-limited and feedback was not given. The ten trials consisted of five presentations of " $\mathrm{C}$ " and " $\mathrm{M}$ " each (the order of which was randomly determined for each participant). The trials were separated by random intervals of 750-1250ms.

Instrumental training. Before the instrumental training phase, the participants were told that they could earn beer and chocolate points by pressing the left and right arrow keys on the keyboard, and that they would only earn rewards on some trials. Each instrumental training trial began with the presentation of a centrally-presented choice symbol (" $\leftarrow$ or $\rightarrow$ "). The participants were free to choose the left or right arrow key on each trial. One response selectively earned beer points, while the other response selectively earned chocolate points. The response-outcome contingencies were counterbalanced across participants. The outcomes were available on half of the trials each; these trials were randomly distributed throughout instrumental training. Left and right arrow key responses were followed by the outcome "You win one [beer/chocolate] point", or "You win nothing" if the response that was associated with the available outcome was not selected. Rewards were presented as points rather than real beer/chocolate to avoid devaluation of the outcomes through satiation (see Colagiuri \& Lovibond, 2015). The outcomes were presented centrally for $1500 \mathrm{~ms}$. There were 24 trials, which were separated by random intervals of $750-$ $1250 \mathrm{~ms}$. We chose these instrumental training parameters to be consistent with our previous work (Seabrooke et al., 2016).

Instrumental knowledge test. Instrumental contingency knowledge was tested immediately after instrumental training. Two questions were presented in a random order: "Which key earned [BEER/CHOCOLATE], the left or right arrow key?" The participants selected an answer using the keyboard. The questions were separated by random intervals of 750-1250ms. 
Transfer test. Before the transfer test, the participants were told that they could continue to earn beer and chocolate points as before, but they would now only be told how many rewards they had earned afterwards. They were also told to expect beer and chocolate pictures on some trials. The reversal instruction ("The pictures indicate which arrow key will NOT be rewarded!") was presented on the initial instruction screen and at the bottom of the screen throughout the transfer test for the Reversal instruction groups. The Load groups were additionally told to expect numbers through their headphones, and to respond in the same way as they did in the practice cognitive load task. The No Load groups, by contrast, were told to not expect numbers through their headphones, but to still expect a number at the end of each trial. They were simply required to select the keyboard button that corresponded to the number shown. Finally, all groups were told that their performance would determine the amount of beer and chocolate they would win. This instruction was deliberately vague with respect to the task (O-R priming task or cognitive load task), to encourage the participants to focus on both tasks.

The transfer test trials followed the procedure of the practice cognitive load task. The Load groups viewed a blank screen for $500 \mathrm{~ms}$, before six numbers sounded through the participants' headphones (330ms each). The numbers were replaced by a blank screen for the equivalent duration (2480ms) in the No Load groups. Following Wills et al. (2011), numbers were not played through the participants' headphones in the No Load groups to prevent the participants from trying to remember the numbers anyway (even if they were instructed not to). All groups then saw a central fixation cross $(500 \mathrm{~ms})$, followed by a blank screen $(500 \mathrm{~ms})$. Either the beer, chocolate or neutral stimulus was then presented, above the choice symbol (“ $\leftarrow$ or $\rightarrow$ "), until a response was performed. No outcomes were given (so that they did not influence response choice), and responding was not time-limited. Finally, a number was presented centrally on-screen. This number was always taken from the first five numbers of the earlier auditory sequence. The Load groups were required to select the number that came next in the sequence (using the keyboard). The No Load groups were simply required to press the key that corresponded to the number shown. There were 
eight cycles of six trials ( 48 trials total), with each stimulus presented twice per cycle (trial order within the cycles was random). The trials were separated by random intervals of $750-1250 \mathrm{~ms}$.

Expectancy ratings. To test expectancy of the cued outcomes, the beer and chocolate stimuli were presented in turn, above the question "When this picture was presented, to what extent did you think that the [beer/chocolate] key was more likely to be rewarded?" The response key [beer/chocolate] was always consistent with the stimulus presented. Participants chose a number between one ("not at all") and seven ("very much"). The questions were randomly ordered and were separated by a 350-750ms interval.

Reward points were not formally translated into real rewards, but participants were offered chocolate at the end of the experiment (regardless of their points tally).

\section{Results}

Upon publication of the manuscript, the trial-level raw data for both experiments will be publicly archived at www.willslab.org.uk.

Instrumental training. A between-subjects analysis of variance (ANOVA) on the percent choice of the beer (versus chocolate) key during the instrumental training phase revealed no significant main effect of Instruction or Load group $\left(F_{s}<2.72, p s>.10\right)$ and no significant interaction, $F(1,57)=1.98, p=.16, \eta_{G}^{2}=.03$. Furthermore, collapsed across groups, choice of the beer response $(M=52.05 \%, S E M=1.87 \%)$ response did not significantly differ from chance, $t(60)=1.10, p=.28$.

Contingency knowledge. Every participant except one reported perfect contingency knowledge in the instrumental knowledge test. Given the low rate of "unaware" participants, no exclusions were made because of contingency knowledge.

Transfer test. Figure 1a shows the mean percent choice of the beer (versus chocolate) response during the transfer test for each group. Figure $1 \mathrm{~b}$ also shows the distribution of percentage scores in each group. A mixed ANOVA was conducted, with percent beer (versus chocolate) choice 
as the dependent variable and independent variables of stimulus (beer, neutral, chocolate), instruction (Non-Reversal, Reversal) and load (No Load, Load). Greenhouse-Geisser corrected $p$ values are reported where necessary to correct for violations of sphericity. There was a main effect of stimulus, $F(2,114)=8.18, p=.002$, generalised eta squared $\left(\eta_{G}^{2}\right)=.10$, but not of instruction condition, $F<1$, or load condition, $F(1,57)=1.77, p=.19, \eta_{G}^{2}=.007$. There was a significant interaction between stimulus and instruction, $F(2,114)=55.60, p<.001, \eta_{G}^{2}=.43$, but not between stimulus and load, $F(2,114)=2.21, p=.13, \eta_{G}^{2}=.03$, or instruction and load, $F<1$. Finally, there was a significant three-way stimulus $\times$ instruction $\times$ load interaction, $F(2,114)=5.94, p=.009, \eta_{G}^{2}$ $=.07$.

The three-way interaction prompted separate analyses in each instruction group. In the Non-Reversal groups, there was a significant effect of stimulus, $F(2,52)=105.48, p<.001, \eta_{G}^{2}=.68$, but not of load group, $F<1$. The stimulus $\times$ load interaction was not significant, $F(2,52)=1.89, p$ $=.16, \eta_{G}^{2}=.04$. The Non-Reversal groups performed more beer responses in the presence of the beer stimulus than the neutral stimulus, $t(27)=6.20, p<.001$, Cohen's $d_{z}=1.17$. Likewise, the chocolate stimulus increased choice of the chocolate response compared to the neutral stimulus, $t$ $(27)=8.08, p<.001, d_{z}=1.53$. Thus, the Non-Reversal groups demonstrated an O-R priming effect, and this effect was not significantly influenced by the cognitive load manipulation.

In the Reversal groups, there was a significant effect of stimulus, $F(2,62)=7.95, p=.005$, $\eta_{G}^{2}=.19$, but not of load group, $F(1,31)=1.43, p=.24, \eta_{G}^{2}=.005$. There was a significant stimulus $\times$ load interaction, $F(2,62)=5.41, p=.02, \eta_{G}^{2}=.13$. In the Reversal No Load group, the beer stimulus increased choice of the chocolate response compared to the neutral stimulus, $t(15)=5.10$, $p<.001, d_{z}=1.28$. Likewise, the chocolate stimulus increased choice of the beer response compared to the neutral stimulus, $t(15)=2.63, p=.02, d_{z}=0.66$. Thus, the Reversal No Load group 
demonstrated a reversed O-R priming effect. The beer and chocolate stimuli did not significantly bias response choice, relative to the neutral stimulus, in the Reversal Load group, $t s<1$.

Non-significant results might either reflect genuine evidence for the null hypothesis, or the data might simply be insufficiently sensitive to distinguish the experimental and null hypotheses. Bayes factors are useful for distinguishing these possibilities. Values greater than three $\left(\mathrm{BF}_{10}>3\right)$ provide evidence for the experimental hypothesis, while values smaller than one third $\left(\mathrm{BF}_{10}<1 / 3\right)$ provide evidence for the null hypothesis. Bayes factors between one third and three suggest that the data are insensitive to distinguish the theories (Dienes, 2011).

A Bayes factor was calculated to explore whether the Reversal Load group showed any evidence of a non-reversal O-R priming effect. To calculate the prior, we assumed that a nonreversal priming effect would be of an equivalent magnitude to that observed in Seabrooke et al.'s (2016) Non-Reversal condition. The percent beer choice on the chocolate trials was subtracted from the beer trials $\left(\mathrm{S}_{\text {beer }}-\mathrm{S}_{\text {chocolate }}\right)$ to calculate the mean difference scores. Using this criterion, Seabrooke et al. (2016) observed a mean difference score of 67.19 in the Non-Reversal group. The equivalent score in the Reversal Load group of the current experiment was -6.99 (SEM = 19.60). A half-normal distribution with the standard deviation set as the plausible mean difference score (67.19) produced a Bayes factor of 0.22. This value is below one third, and therefore supports the suggestion that the stimuli did not bias response choice in the Reversal Load condition.

Figure $1 \mathrm{c}$ shows the mean transfer test reaction times for each stimulus and group. The graph suggests that the Non-Reversal groups responded to the beer and chocolate stimuli more quickly than the Reversal instruction groups. The neutral stimulus was omitted from the analysis because our primary interest was with respect to the beer and chocolate stimuli. The Non-Reversal groups responded more quickly than the Reversal groups, $F(1,57)=7.78, p=.007, \eta_{G}^{2}=.11$. None of the other main effects or interactions approached significance $(F s<2.22, p s>.14)$. 
Expectancies. Figure 1d shows the mean expectancy ratings for each outcome and group.

Most importantly, the Reversal groups gave lower expectancy ratings than the Non-Reversal groups, $F(1,57)=22.47, p<.001, \eta_{G}^{2}=.26$. Chocolate also received higher ratings than beer, $F(1,57)=4.61$, $p=.04, \eta_{G}^{2}=.009$. There was no significant effect of load group, $F(1,57)=2.36, p=.13, \eta_{G}^{2}=.04$. There was a significant instruction $\times$ load interaction, $F(1,57)=7.28, p=.009, \eta_{G}^{2}=.10$, but none of the interactions involving the outcome factor approached significance $(F s<1.27, p s>.26)$.

The instruction $\times$ load interaction prompted separate Welch two sample $t$-tests in each instruction group. No significant effect of load was observed in the Non-Reversal instruction groups, $t(53.66)=1.31, p=.20$, Cohen's $d=0.35$. The Reversal Load group gave higher expectancy ratings than the Reversal No Load group, $t(60.02)=3.75, p<.001, d=0.92$, suggesting that the Load group were less receptive to the reversal instruction group than the No Load group.

Figure 1e shows the relationship between expectancy ratings and the size of the overall transfer effect in each instruction group. The overall transfer effect reflects the extent to which the beer and chocolate stimuli increased choice of the associated response during the transfer test, relative to the neutral stimulus. Response choice was always coded as the percent choice of the beer response. Thus, the beer transfer effect was calculated by subtracting beer choice on the neutral stimulus trials from the beer stimulus trials $\left(S_{\text {beer }}-S_{\text {neutral }}\right)$. The chocolate transfer effect was calculated by subtracting beer choice on the chocolate stimulus trials from the neutral stimulus trials $\left(S_{\text {neutral }}-S_{\text {chocolate }}\right)$. The overall transfer effect reflects the mean of the beer and chocolate transfer effects. Transfer effect scores correlated positively with self-reported expectancy ratings, $r=.75, p$ $<.001$. This correlation was significant in both the Non-Reversal, $r=.61, p<.001$, and Reversal instruction groups, $r=.67, p<.001$. These correlations did not significantly differ in size, $w=.39, p$ $=.70$. 


\section{Discussion}

Consistent with prior studies, the Non-Reversal No Load group demonstrated an O-R priming effect, where the reward cues selectively increased the response that predicted the common outcome (e.g., Hogarth, 2012; Martinovic et al., 2014; Seabrooke et al., 2016, 2017, Watson et al., $2017,2016)$. Furthermore, an O-R priming effect was observed even under cognitive load. This resistance to load suggests that, at least in the current procedure, O-R priming effects do not require a great deal of controlled processing capacity.

The Reversal No Load group also demonstrated a reversed O-R priming effect, where the reward cues increased the response that was most likely to be reinforced according to the instruction, rather than the most strongly cued response. The Reversal Load group, by contrast, responded at chance during the transfer test. The Reversal Load group did not, therefore, show evidence of automaticity. Rather, they appeared to abandon their attempt to respond systematically during the transfer test. The results of Experiment 1 collectively provide support for both the automatic and controlled theories of O-R priming effects, and so the interpretation of these data is resumed in the General Discussion.

Although response choice during the transfer test was the primary measure of interest in Experiment 1, there were some other noteworthy results. First, the Reversal groups were slower to respond to the reward cues than the Non-Reversal groups. This result bears resemblance to classic two-stage ideomotor priming effects (Elsner \& Hommel, 2001). In a typical two-stage priming task, participants first learn to perform two responses, which are each followed by either a high or a low tone outcome (R1-O1, R2-O2). These tones are subsequently presented and participants are required to select a response as quickly and as accurately as possible. For an action-consistent group, the mapping of response to outcome is congruent in the training and test phases; participants should perform R1 and R2 when $\mathrm{O} 1$ and $\mathrm{O} 2$ are presented, respectively. The mappings are reversed for an action-inconsistent group (O1-R2 and O2-R1). Importantly, the action-consistent group usually 
respond more quickly than the action-inconsistent group (e.g., Elsner \& Hommel, 2001; Flach, Osman, Dickinson, \& Heyes, 2006; Watson, van Steenbergen, de Wit, Wiers, \& Hommel, 2015). The automatic activation of the trained responses is therefore suggested to interfere with the execution of the instructed responses in the action-inconsistent group. It should be noted that there are a number of procedural differences between the current task and Elsner and Hommel's (2001) twostage priming task. First, participants were not encouraged to respond quickly during the current test phase. Participants in two-stage priming tasks also need not remember the original trained contingencies, because the tested contingencies are explicitly instructed before the test phase. By contrast, the Reversal groups of Experiment 1 here needed to combine their knowledge of the trained contingencies with the novel instruction, because the reversal instruction did not explicitly specify the instructed relations. Hence, caution must be taken when comparing the two tasks. Nevertheless, the current results are interesting because they complement previous ideomotor results within the context of an O-R priming experiment.

Consistent with previous studies, expectancy ratings were also related to O-R priming effect scores during the transfer test (Hardy et al., 2017; Hogarth et al., 2014; Seabrooke et al., 2016). This correlation (as well the observed instructional sensitivity) is consistent with the suggestion that conscious, verbalisable beliefs play an important role in O-R priming effects.

\section{Experiment 2}

Experiment 1 demonstrated a reversed O-R priming effect that was abolished by cognitive load. The non-reversal O-R priming effect, by contrast, was robust against the cognitive load task. The latter result was observed under conditions that usually produce O-R priming effects that are insensitive to devaluation manipulations (Seabrooke et al., 2017, Experiment 1). Collectively, these results accord with the suggestion that this typical O-R priming procedure produces seemingly automatic responses. 
Experiment 2 extended the approach of Experiment 1 to explore whether a cognitive load task would produce automatic responding in an O-R priming procedure that otherwise produces goal-directed response choice (Seabrooke et al., 2017, Experiment 3). Table 1 shows the design. Participants first learn to perform two instrumental responses (R1 and R2) to earn points towards three different outcomes (01-03; crisps, popcorn and cashew nuts - counterbalanced). Both responses produce $\mathrm{O} 3$ on half of the trials. On the remaining trials, $\mathrm{R} 1$ responses produce $\mathrm{O} 1$ and $\mathrm{R} 2$ responses produce 02 . Outcomes $\mathrm{O} 1$ and $\mathrm{O} 2$ are then devalued so that each instrumental response is associated with one valued outcome (O3) and one devalued outcome ( $\mathrm{O} 1 \mathrm{or} \mathrm{O} 2$ ). Instrumental response choice is finally assessed in the presence of one of two stimulus compounds: S1+S3 (stimuli that signal $\mathrm{O} 1$ and $\mathrm{O3}$ ) or S2+S3 (stimuli that signal $\mathrm{O} 2$ and 03 ).

This design is particularly useful because automatic and goal-directed processes should produce opposite results. An automatic O-R priming effect would be revealed by a selective bias towards the most strongly signalled response, regardless of the devaluation manipulation. This is because, by definition, an automatic process is not goal-directed (de Wit \& Dickinson, 2009; Dickinson, 1985). Thus, the S1+S3 compound should increase R1 responses, because R1 was paired with both of the cued outcomes (O1 and O3), whereas the R2 response was paired with only one of the cued outcomes - O3. The S2+S3 compound should similarly increase R2 responses. A goaldirected agent, by contrast, should perform in such a way that they avoid the devalued outcome that is cued. Thus, the $\mathrm{S} 1+\mathrm{S} 3$ compound should promote $\mathrm{R} 2$ responses, to avoid the cued, devalued O1. Likewise, the S2+S3 compound should promote R1 responses, to avoid the cued, devalued $\mathrm{O} 2$.

Seabrooke et al. (2017) observed a clear goal-directed O-R priming effect using this procedure. Response choice was biased not towards the most strongly signalled response, but away from the response that predicted the cued, devalued outcome. This result suggests that O-R priming effects are highly sensitive to outcome devaluation manipulations when multiple outcomes and responses are cued together during the transfer test. The current Experiment 2 examined whether 
this goal-directed O-R priming effect would give way to an automatic priming effect when participants' controlled processing capacity was consumed by Wills et al.'s (2011) cognitive load task. Such an effect would be revealed by a bias towards the most strongly cued response, irrespective of the devaluation manipulation. This result would look much more like the insensitivity to devaluation that is usually seen in typical O-R priming procedures (e.g., Experiment 1), where one cue is presented alone during the transfer test.

Participants were randomly allocated to a load condition (No Load or Load) at the start of the experiment. The No Load group followed a very similar procedure to that of Seabrooke et al. (2017). The Load group also completed the cognitive load task of Experiment 1 during the transfer test. We expected to replicate Seabrooke et al.'s (2017) goal-directed O-R priming effect in the No Load group. The question was whether the Load group would show evidence of insensitivity to the devaluation manipulation during the transfer test. Such a result would be revealed if the $\mathrm{S} 1+\mathrm{S} 3$ and $\mathrm{S} 2+\mathrm{S} 3$ compounds biased response choice towards $\mathrm{R} 1$ and $\mathrm{R} 2$, respectively.

\section{Method}

Participants. Fifty-five participants ( 35 females, aged between 18 and 30, $M=21.15$ years, $S E M=0.41$ years) from Plymouth University completed the experiment for $f 4$. The participants had not completed Experiment 1. The participants were randomly allocated to the No Load $(N=28)$ or Load $(N=27)$ group at the start of the experiment. The experiment was approved by the Plymouth University Ethics Committee.

Apparatus and materials. Salted snack foods were used as outcomes to be consistent with Seabrooke et al.'s (2017) outcome devaluation procedure. Unopened bags of Walker's extra crunchy ready salted crisps (150g), Tyrrell's sea salted popcorn (70g), and Sainsbury's salted jumbo cashew nuts (400g) served as visual props. These brands were also used for the devaluation manipulation; before the experiment, the outcomes were decanted into separate transparent containers, with the food name written on the lid. For the devaluation manipulation, ground cloves were combined with 
olive oil (11g oil per $5 \mathrm{~g}$ cloves) to form a paste that was brushed heavily onto the devalued foods. The valued outcome was simply transferred from the original packaging to its container. All other aspects of the apparatus and materials were identical to Experiment 1.

Procedure. Participants were warned before the experiment that they would be required to sample foods during the experiment, that they may not match their expectations, and that they may taste unpleasant. Once informed consent had been obtained, the food props were presented and the participants were told they could win points towards them during the experiment. The props were placed in front of the computer screen, in a consonant location to the keys that produced them (i.e., $\mathrm{O} 3$ was placed centrally, and $\mathrm{O} 1$ and $\mathrm{O} 2$ were placed to the left and right of $\mathrm{O3}$, respectively). Both groups completed each stage of the experiment.

Practice cognitive load task. The practice cognitive load task was very similar to that used in Experiment 1. The letter " $\mathrm{C}$ " or " $\mathrm{M}$ " appeared at the top- and bottom-centre of the screen on each trial, and the participants were required to press the corresponding key. The letter stimuli were presented from the start of the trial, and were therefore present during the number sequence. The statement "Press the key" appeared centrally when a response was required. All other aspects of the practice cognitive load task were identical to that of Experiment 1.

Liking ratings. After the practice cognitive load task, participants rated how much they would like to eat each food in a random order (1 = "not at all", 7 = "very much").

Instrumental training. The instrumental training phase was similar to that of Experiment 1, although some minor procedural changes were implemented to allow comparison with Seabrooke et al.'s (2017) original experiment. The participants were told that they could win the three food outcomes by pressing the " $\mathrm{A}$ " and " $\mathrm{L}$ " keys on the keyboard, which served as R1 and R2, respectively. They were informed that both keys would produce the food that served as $\mathrm{O3}$, and that they should learn which keys produced the outcomes that served as $\mathrm{O} 1$ and $\mathrm{O} 2$. The food props were removed 
after the instrumental training instructions had been explained. Each instrumental training trial began with the central presentation of the statement "Choose a key: A or L?", which remained onscreen until a response was performed. Outcome $\mathrm{O} 3$ was scheduled to be available on half of the trials; $\mathrm{O} 1$ and $\mathrm{O} 2$ were available on the remaining trials. The food outcomes were counterbalanced with respect to the outcomes they served as. When 03 was available, both instrumental responses produced that outcome. When $\mathrm{O} 1$ and $\mathrm{O} 2$ were available, the " $\mathrm{A}$ " key produced $\mathrm{O} 1$ and the " $\mathrm{L}$ " key produced O2. Rewards were presented as "You earn one [CRISPS/POPCORN/CASHEWS] point" for $3000 \mathrm{~ms}$, depending on the outcome earned. The outcome (crisps/popcorn/cashews) was presented in bold text. There were 48 trials, which were randomly distributed throughout the training phase with respect to outcome availability.

Instrumental knowledge test. Explicit awareness of the instrumental contingencies was tested using a similar procedure to Experiment 1. Three questions were presented in a random order: "Which key earned [CRISPS/POPCORN/CASHEWS]?" Participants selected between three on-screen options ("A key", "Both" and "L key") using the mouse. Participants also rated their confidence after each question ( 1 = "not at all confident", 7 = "very confident"). The questions were separated by random intervals of 750-1250ms.

Outcome devaluation. Participants then sampled each outcome and were told that those were the foods that were now available for them to win. The valued outcome 03 was always presented and sampled first, before the devalued outcomes were revealed. 01 and $\mathrm{O} 2$ were then revealed and sampled in a random order. Afterwards, the three food outcomes were placed in front of the computer and a second set of liking ratings were recorded for each outcome. The foods were removed before the start of the main transfer test.

Transfer test. The transfer test followed a similar procedure to Experiment 1; participants were informed that they could continue earning the food outcomes as before, but that they would now only be told how many rewards they had earned at the end. They were also told that pictures of 
the foods would sometimes be presented, and that the location of the pictures was not important. Consistent with Seabrooke et al. (2017), the participants were also told that they would be required to eat all of the food earned at the end of the experiment. Note that the participants did not actually consume the outcomes after the experiment for ethical reasons; the instruction was given simply to strengthen the devaluation manipulation (see Eder \& Dignath, 2016b).

The Load group was told to expect numbers through their headphones, and to respond to those numbers in the same way as in the practice cognitive load task. The No Load group was told not to expect numbers through their headphones, but to simply press the corresponding key on the keyboard when a number appeared at the end of each trial.

The transfer test followed the same procedure as the practice cognitive load task in the Load condition. Each trial began with the presentation of two pictorial stimuli that depicted the outcomes. The stimuli were always presented at the top centre and bottom centre of the screen. Stimulus S3 (depicting the valued O3) was present on every trial, alongside either S1 or S2 (depicting the devalued $\mathrm{O} 1$ and $\mathrm{O2}$, respectively). The location of the stimuli was counterbalanced across trials, thereby creating four trial types $(\mathrm{S} 1+\mathrm{S} 3$ and $\mathrm{S} 2+\mathrm{S} 3$, with counterbalanced cue location). The stimuli always depicted the outcomes in their valued state. Immediately following the onset of the stimuli, the number sequence was presented in the same way as in Experiment 1. The six numbers were presented at $330 \mathrm{~ms}$ intervals $(1980 \mathrm{~ms}$ in total). The numbers were not presented in the No Load group; the stimulus compounds were simply presented on-screen for $1980 \mathrm{~ms}$. Then, the choice statement from the instrumental training phase (“Choose a key: A or L?") appeared centrally, between the two stimuli, until participants selected either the " $A$ " or " $L$ " key. Finally, a number from the first five numbers from the earlier number sequence was presented centrally on-screen. The Load group was required to select the number that came next in the sequence, while the No Load group was required to select the corresponding key on the keyboard. The trials were separated by random intervals of 750-1250ms. There were eight cycles, which each consisted of one presentation 
of each of the four trial types ( 32 trials total). The trial order was random in each cycle. Participants completed one practice cycle before continuing on to the main transfer test.

Expectancy ratings and knowledge tests. After the transfer test, expectancy ratings were recorded for each stimulus and outcome in the same way as in Experiment 1. A final liking test was also administered. To check whether the participants retained explicit awareness of the instrumental contingencies during the transfer test, a second instrumental knowledge test (which was identical to the first) was administered. A stimulus knowledge test was also administered; the three pictorial stimuli were presented in a random order and the participants were asked to select which outcome the stimulus depicted. As in Experiment 1, participants were offered chocolate at the end of the experiment, but reward points were not formally translated into rewards.

\section{Results}

Instrumental training. The percent choice of the R1 (versus R2) response during the instrumental training phase did not significantly differ between the No Load $(M=46.65 \%, S E M=$ $4.63 \%)$ and Load $(M=47.92 \%, S E M=4.09 \%)$ groups, $t<1$. Choice of the two responses did not significantly differ from chance in either group, $t s<1$.

Contingency knowledge. Thirty-eight participants (69.09\% of the sample) reported perfect contingency knowledge in the instrumental and picture knowledge tests. These participants were labelled 'aware'; the remaining participants were considered to be 'partially aware' (every participant answered some questions correctly).

Confidence ratings were also recorded during the instrumental knowledge tests. Across the complete dataset, participants were more confident in their instrumental knowledge before the transfer test $(M=6.51, S E M=0.09)$ than they were afterwards $(M=4.58, \operatorname{SEM}=0.18), F(1,53)=$ $65.36, p<.001, \eta_{G}^{2}=.31$. Confidence ratings were also higher for the valued $03(M=5.71$, SEM $=$ $0.16)$ than the devalued $01 / O 2(M=5.38, \operatorname{SEM}=0.17), F(1,53)=7.49, p=.008, \eta_{G}^{2}=.01$. This result 
is unsurprising because the participants were told that both responses would produce 03 . No significant effect of group was observed, $F<1$. There was a significant test $\times$ outcome interaction, $F$ $(1,53)=6.64, p=.01, \eta_{G}^{2}=.006$. None of the remaining interactions reached significance $\left(F_{\mathrm{s}}<2.30\right.$ $p s>$.14). Confidence ratings were higher for $03, t(54)=6.70, p<.001, d_{z}=0.90$ and $01 / 02, t(54)=$ $8.57, p<.001, d_{z}=1.15$, in the first knowledge test than in the second knowledge test.

Liking ratings. The mean pre- and post-devaluation liking ratings are reported in Table 2. A mixed ANOVA on the liking rating data was conducted, with the outcomes (devalued 01/02 vs. valued O3) and liking test (pre- vs. post-devaluation) as within-subjects factors and group (No Load vs. Load) as a between-subjects factor. There was a main effect of outcome, with the valued 03 receiving higher ratings than the devalued $01 / 02, F(1,53)=227.04, p<.001, \eta_{G}^{2}=.55$. A main effect of liking test was also observed, with higher ratings given at the beginning of the experiment than after the devaluation manipulation, $F(1,53)=50.91, p<.001, \eta_{G}^{2}=.12$. There was no significant effect of group, $F<1$. Most importantly, there was a significant liking test $\times$ outcome interaction, $F(1,53)=291.82, p<.001, \eta_{G}^{2}=.54$. None of the remaining interactions approached significance, $F_{s}<1$. Ratings for $01 / 02$ and 03 did not significantly differ before devaluation, $t<1$. The valued 03 received significantly higher ratings than the devalued $01 / 02$ after the devaluation manipulation, $t(54)=29.80, p<.001, d_{z}=4.02$. This latter result shows that the devaluation manipulation produced a strong devaluation of $\mathrm{O} 1$ and $\mathrm{O} 2$, and potentially an increase of liking for $\mathrm{O} 3$ in the context of $\mathrm{O} 1$ and $\mathrm{O} 2$.

Transfer test. Figure 2a shows the percent choice of R1 (versus R2) in each load condition during the transfer test (collapsed across contingency awareness groups). A mixed ANOVA revealed a main effect of stimulus compound, with the $\mathrm{S} 2+\mathrm{S} 3$ compound eliciting more $\mathrm{R} 1$ responses than the S1 + S3 compound, $F(1,53)=4.33, p=.04, \eta_{G}^{2}=.01$. There was no significant effect of group, $F<1$, 
nor was there a significant stimulus compound $\times$ group interaction, $F(1,53)=2.66, p=.11, \eta_{G}^{2}$

$=.009^{2}$.

We repeated the above analysis on the subset of participants that reported perfect contingency knowledge (No Load, $N=18$; Load, $N=20$ ), because there is substantial evidence to suggest that traditional PIT effects require explicit contingency knowledge (Bezzina, Lee, Lovibond, \& Colagiuri, 2016; Hogarth et al., 2007; Lovibond, Satkunarajah, \& Colagiuri, 2015; Talmi, Seymour, Dayan, \& Dolan, 2008; Trick, Hogarth, \& Duka, 2011). Unfortunately, an equivalent analysis on the partially aware group would have been extremely underpowered because of the small number of partially aware participants in each group (No Load, $N=10$; Load, $N=7$ ). We therefore restricted our analysis to the aware group (although note that the data are publicly available for interested readers). Figures $2 \mathrm{~b}$ shows the results. There was a main effect of stimulus compound, with the $\mathrm{S} 2+\mathrm{S} 3$ compound eliciting more $\mathrm{R} 1$ responses than the $\mathrm{S} 1+\mathrm{S} 3$ compound, $F(1,36)=5.07, p=.03, \eta_{G}^{2}$ $=.02$. A significant main effect of group was not observed, $F<1$. Most importantly, there was a significant stimulus compound $\times$ group interaction, $F(1,36)=6.40, p=.02, \eta_{G}^{2}=.03$. Follow up $t$ tests showed that the $\mathrm{S} 2+\mathrm{S} 3$ compound elicited more $\mathrm{R} 1$ responses than the $\mathrm{S} 1+\mathrm{S} 3$ compound in the No Load group, $t(17)=2.36, p=.03, d_{z}=0.56$. No significant effect of stimulus compound was observed in the Load group, $t<1$.

A Bayes factor was calculated to determine whether the Load group showed any evidence of a standard O-R priming effect. To calculate the prior, we assumed that the priming effect would be of an equivalent magnitude to Seabrooke et al.'s (2017) effect, but in the opposite direction. A transfer effect score was calculated by subtracting the percent choice of the R1 response on $\mathrm{S} 2+\mathrm{S} 3$ trials from $\mathrm{S} 1+\mathrm{S} 3$ trials $(\mathrm{S} 1+\mathrm{S} 3-\mathrm{S} 2+\mathrm{S} 3$ ). Using this calculation, Seabrooke et al. (2017) observed a mean difference score of -50.96 . The equivalent score in the Load group of the current experiment

\footnotetext{
${ }^{2}$ The non-significant interaction might reflect a lack of power, meaning that conclusions must be
} 
was $1.25(S E M=2.38)$. For the Bayes calculation we assumed a plausible mean difference score of Seabrooke et al.'s (2017) but in the opposite direction, and so the prior was set as 50.96. A halfnormal distribution with the standard deviation set as the plausible mean difference score (50.96) produced a Bayes factor of 0.07 . This value is below one third, and therefore supports the suggestion that the stimulus compounds did not bias response choice in the Load condition.

Expectancies. Across the whole sample, a trend was observed towards the No Load group $(M=4.49, S E M=0.25)$ giving higher expectancy ratings than the Load group $(M=3.63, S E M=0.25)$, $F(1,53)=3.86, p=.05, \eta_{G}^{2}=.05$. No significant main effect of stimulus (S1/S2 versus S3), $F(1,53)=$ $2.41, p=.13, \eta_{G}^{2}=.01$, or stimulus $\times$ group interaction, $F<1$, was observed. The pattern did not change when the analysis was repeated on only the contingently aware participants ( $F s<2.39$, ps > .13).

\section{Discussion}

Experiment 2 replicated Seabrooke et al.'s (2017) goal-directed O-R priming effect in the No Load group. When both a high- and low-value outcome were cued together during the transfer test, response choice was biased not towards the most strongly cued response, but towards the response that did not predict the cued, devalued outcome. Notably, the cognitive load task abolished this goal-directed O-R priming effect. Crucially, the Load group showed no evidence of an automatic O-R priming effect that was insensitive to the devaluation manipulation. These participants responded at chance throughout the transfer test, regardless of the stimulus compound present.

\section{General Discussion}

Two experiments examined the effect of cognitive load on O-R priming effects. Both experiments incorporated a test of controlled cognition that has been used previously; Experiment 1 replicated a previous finding that O-R priming effects can be reversed by instruction (Seabrooke et

drawn with caution. 
al., 2016), while Experiment 2 replicated a demonstration that such effects are, under certain circumstances, goal-directed (Seabrooke et al., 2017). Both of these findings support the suggestion that controlled processes play an important role in O-R priming effects. The two experiments also provided new findings related to the effect of cognitive load. First, the standard O-R priming effect, in which a single cue signals a single outcome that has been associated with a single response (henceforth the "standard" O-R priming effect), was robust against the cognitive load manipulation in Experiment 1. This suggests that the standard effect does not require a great deal of controlled processing capacity. Second, the reversed O-R priming effect in Experiment 1 was abolished by the cognitive load task; the Reversal Load group responded at chance during the transfer test. Finally, cognitive load abolished the goal-directed pattern of response choice that was otherwise seen in Experiment 2; the Load group showed chance responding on test.

Other possible effects of automaticity were not observed. In both experiments, the imposition of cognitive load had the potential to reveal automaticity by producing the opposite effect to that seen in the No Load groups. The instructed reversal effect of Experiment 1 could have been eliminated by imposing load, thereby providing the potential to reveal any underlying automaticity in the Reversal Load group. This was not seen. Similarly, a priming effect that was insensitive to the outcome devaluation manipulation might have been revealed under load in Experiment 2. No automaticity was revealed in this way.

Some aspects of the results are consistent with the idea that there are two qualitatively different forms of O-R priming. The resistance of the standard priming effect to cognitive load in Experiment 1 suggests that, in the typical procedure, O-R priming effects might have an automatic quality. The credibility of this suggestion hinges on strength of the cognitive load manipulation; weaker cognitive load tasks should, of course, have less impact on performance than stronger cognitive load tasks. To the extent that the insensitivity of the standard priming effect of Load does provide evidence of "automaticity", it is consistent with the insensitivity to devaluation that is seen 
in the standard O-R priming design (Hogarth, 2012; Hogarth \& Chase, 2011), which is likewise taken as evidence of automaticity. The instructed reversal seen in Experiment 1 and the goal-directed behaviour seen in Experiment 2 (in the No Load conditions), however, seems to reflect higher level, cognitive processes. These more complex priming effects would be expected to require cognitive resources and should therefore be diminished by cognitive load, as was observed. Hence, the overall pattern of results is consistent with the idea that there are two ways in which outcome cues can potentiate instrumental responding in an outcome-selective fashion. The simple case, where a single cue signals a single outcome that can be earned by a single response, does not seem to require a great deal of cognitive capacity. This can be contrasted with a more resource-dependent form of O-R priming, where participants' choices require an integration of information. In the instructed reversal case, the instruction must be combined with knowledge of the trained contingencies. Similarly, the goal-directed O-R priming effect of Experiment 2 requires an integration of knowledge of the instrumental contingencies with knowledge of the outcome values. These more complex priming effects seem to reflect the operation of controlled reasoning processes.

The insensitivity of the standard O-R priming effect to cognitive load (Experiment 1 ) could be construed as evidence of automaticity, but it is worth emphasising that the data do not demand this interpretation. The results of Experiment 1 are equally consistent with the idea that standard O-R priming effects involve the application of a very simple rule, for example, "if popcorn stimulus, then choose popcorn response". Such a rule would be very easy to abide by, even when distracted by a cognitive load task. Furthermore, this rule does not invoke outcome value, so it would also be consistent with the observed insensitivity of the standard O-R priming effect to outcome devaluation manipulations. It might be argued that this simple rule is not automatic in any absolute sense; all rules require cognitive resources. However, automaticity is widely regarded as relative rather than absolute (Moors \& De Houwer, 2006). There is a continuum in terms of the speed of a given response, the extent to which the subject can control that response, and the cognitive resources 
that the response requires. What can be said about the simple rule, then, is that it should be very easy to apply and should therefore be relatively automatic.

Although resistance to cognitive load suggests that the standard O-R priming effect may be (to some extent) automatic, other aspects of our data weaken this argument. As described above, cognitive load eliminated the reversed priming effect in Experiment 1 and the goal-directed priming effect in Experiment 2. However, no automatic standard priming effect was revealed by imposing load in either of the conditions that provided clear demonstrations of cognitive control: reversal instructions in Experiment 1 and goal-directed action in Experiment 2. This is despite the fact that the load task demonstrably consumed significant controlled processes - enough to eliminate both the reversed effect and the goal-directed effect. If we take the standard O-R priming effect seen in the Non-Reversal Load group of Experiment 1 as evidence for automaticity, it is surprising that the load task did not also reveal an underlying automatic priming effect in the more complex O-R priming tasks.

How do we interpret the failure of cognitive load to reveal automaticity in the Reversal Load (Experiment 1) and Load (Experiment 2) conditions? There are at least two possibilities. First, the load task might not have consumed all of the available cognitive resources. Responding could then have been driven partly by a controlled process and partly an automatic process. These two processes may have then cancelled one another out, because they should facilitate opposite patterns of responding. One might be forgiven, however, for being sceptical that the controlled and automatic processes exactly cancelled out in both experiments. An alternative interpretation is that, in the face of the cognitive load task and the more complex reversal or goal-directed O-R priming task, participants abandoned any attempt to respond systematically because of the overwhelming amount of information that they were required to process. This analysis suggests that the resistance to cognitive load seen in the Non-Reversal group of Experiment 1 was not the result of an automatic 
mechanism because, if it were, that automatic mechanism should also have controlled responding in the Reversal Load and Load group of Experiments 1 and 2, respectively.

We could potentially set the two explanations described above against one another by increasing the demands of the cognitive load task. A more challenging cognitive load task might reveal a standard O-R priming effect in the Reversal Load condition of Experiment 1 and the Load condition of Experiment 2 (as opposed to the chance performance seen in the current experiments). These results would support the idea that standard O-R priming effects can be automatic. Alternatively, stronger cognitive load might attenuate the standard O-R priming effect that was seen in the Non-Reversal Load condition of Experiment 1. This result would support the suggestion that standard O-R priming effects are mediated, at least to some degree, by controlled reasoning processes.

The development and testing of a new and more potent load task would require a program of investigation that is outside the scope of the current research. It is not a straightforward matter to produce the exact level of cognitive load required to "lesion" high-level functioning, but leave all of the necessary perceptual processes intact to allow a putative simple, stimulus-based mechanism to operate. It should also be noted that the level of load used here successfully prevented high-level cognitive processing and consequently revealed an apparently simpler mechanism in a previous study (Wills et al., 2011). Hence, it may be difficult to improve upon the current study by manipulating levels of load. It is also not clear that a stronger cognitive load task would provide conclusive evidence for or against the rule-based and automatic hypotheses. For example, the application of a very challenging load task might lead to apparently chance responding in the NonReversal Load condition in Experiment 1. On the face of it, this would be consistent with the idea that a simple rule mediates the standard O-R priming effect; a truly automatic mechanism might be expected to survive any level of load. Another interpretation is, however, possible. The stronger cognitive load might have abolished the required perceptual processing of the stimuli, which would 
prevent the operation of both controlled and automatic processes. Thus, a stronger cognitive load task would not necessarily resolve the issue.

To conclude, Experiment 1 provided some evidence of automaticity; the standard O-R priming effect was insensitive to cognitive load. This seemingly automatic priming effect could be driven by either an associative link-based mechanism or a very simple rule. Both experiments also replicated earlier demonstrations that O-R priming effects can be controlled; they provided evidence of instructed reversal (Experiment 1; Seabrooke et al., 2016) and sensitivity to outcome devaluation (Experiment 2; Seabrooke et al., 2017). Together, the results suggest that reward-associated cues can influence instrumental choice in a controlled fashion. Those choices may also, under certain circumstances, have features of automaticity. 


\section{References}

Alarcón, D. E., \& Bonardi, C. (2016). The effect of conditoned inhibition on the specific Pavlovianinstrumental transfer effect. Journal of Experimental Psychology: Animal Learning and Cognition, 42(1), 82-94. https://doi.org/http://dx.doi.org/10.1037/xan0000087

Alarcón, D. E., Bonardi, C., \& Delamater, A. R. (2017). Associative mechanisms involved in specific Pavlovian-to-instrumental transfer (PIT) in human learning tasks. The Quarterly Journal of Experimental Psychology. https://doi.org/10.1080/17470218.2017.1342671

Allman, M. J., DeLeon, I. G., Cataldo, M. F., Holland, P. C., \& Johnson, A. W. (2010). Learning processes affecting human decision making: An assessment of reinforcer-selective Pavlovianto-instrumental transfer following reinforcer devaluation. Journal of Experimental Psychology: Animal Behavior Processes, 36(3), 402-408. https://doi.org/10.1037/a0017876

Baguley, T. (2012). Calculating and graphing within-subject confidence intervals for ANOVA. Behavior Research Methods, 44(1), 158-175. https://doi.org/10.3758/s13428-011-0123-7

Balleine, B. W., \& O'Doherty, J. P. (2010). Human and rodent homologies in action control: Corticostriatal determinants of goal-directed and habitual action. Neuropsychopharmacology, 35(1), 48-69. https://doi.org/10.1038/npp.2009.131

Bezzina, L., Lee, J. C., Lovibond, P. F., \& Colagiuri, B. (2016). Extinction and renewal of cue-elicited reward-seeking. Behaviour Research and Therapy, 87, 162-169. https://doi.org/10.1016/j.brat.2016.09.009

Cartoni, E., Moretta, T., Puglisi-Allegra, S., Cabib, S., \& Baldassarre, G. (2015). The relationship between specific pavlovian instrumental transfer and instrumental reward probability. Frontiers in Psychology, 6(NOV), 1-7. https://doi.org/10.3389/fpsyg.2015.01697

Cohen-Hatton, S. R., Haddon, J. E., George, D. N., \& Honey, R. C. (2013). Pavlovian-to-instrumental 
transfer: Paradoxical effects of the Pavlovian relationship explained. Journal of Experimental Psychology: Animal Behavior Processes, 39(1), 14-23. https://doi.org/10.1037/a0030594

Colagiuri, B., \& Lovibond, P. F. (2015). How food cues can enhance and inhibit motivation to obtain and consume food. Appetite, 84, 79-87. https://doi.org/10.1016/j.appet.2014.09.023

Colwill, R. M., \& Rescorla, R. A. (1988). Associations between the discriminative stimulus and the reinforcer in instrumental learning. Journal of Experimental Psychology: Animal Behavior Processes, 14(2), 155-164. https://doi.org/10.1037/0097-7403.14.2.155

Colwill, R. M., \& Rescorla, R. A. (1990). Effect of reinforcer devaluation on discriminative control of instrumental behavior. Journal of Experimental Psychology. Animal Behavior Processes, 16(1), 40-47. https://doi.org/10.1037/0097-7403.16.1.40

Corbit, L. H., \& Balleine, B. W. (2005). Double dissociation of basolateral and central amygdala lesions on the general and outcome-specific forms of pavlovian-instrumental transfer. Journal of Neuroscience, 25(4), 962-970. https://doi.org/10.1523/JNEUROSCI.4507-04.2005

Corbit, L. H., Janak, P. H., \& Balleine, B. W. (2007). General and outcome-specific forms of Pavlovianinstrumental transfer: The effect of shifts in motivational state and inactivation of the ventral tegmental area. European Journal of Neuroscience, 26(11), 3141-3149. https://doi.org/10.1111/j.1460-9568.2007.05934.x

De Houwer, J., \& Beckers, T. (2003). Secondary task difficulty modulates forward blocking in human contingency learning. The Quarterly Journal of Experimental Psychology B: Comparative and Physiological Psychology, 56(4), 345-357. https://doi.org/10.1080/02724990244000296

de Wit, S., \& Dickinson, A. (2009). Associative theories of goal-directed behaviour: A case for animalhuman translational models. Psychological Research, 73(4), 463-476.

https://doi.org/10.1007/s00426-009-0230-6 
de Wit, S., \& Dickinson, A. (2015). Ideomotor mechanisms of goal-directed behavior. In T. S. Braver (Ed.), Motivation and Cognitive Control (pp. 123-142). New York: NY: Routledge.

de Wit, S., Ridderinkhof, K. R., Fletcher, P. C., \& Dickinson, A. (2013). Resolution of outcome-induced response conflict by humans after extended training. Psychological Research, 77(6), 780-793. https://doi.org/10.1007/s00426-012-0467-3

Dickinson, A. (1985). Actions and habits: the development of behavioural autonomy. Philosophical Transactions of the Royal Society of London. Series B, Biological Sciences, 308(1135), 67-78. https://doi.org/10.1098/rstb.1985.0010

Dickinson, A., Balleine, B., Watt, A., Gonzalez, F., \& Boakes, R. A. (1995). Motivational control after extended instrumental training. Animal Learning \& Behavior, 23(2), 197-206. https://doi.org/10.3758/BF03199935

Dienes, Z. (2011). Bayesian versus orthodox statistics: which side are you on? Perspectives on Psychological Science, 6(3), 274-290. https://doi.org/10.1177/1745691611406920

Eder, A. B., \& Dignath, D. (2016a). Asymmetrical effects of posttraining outcome revaluation on outcome-selective Pavlovian-to-instrumental transfer of control in human adults. Learning and Motivation, 54, 12-21. https://doi.org/10.1017/СВ09781107415324.004

Eder, A. B., \& Dignath, D. (2016b). Cue-elicited food seeking is eliminated with aversive outcomes following outcome devaluation. Quarterly Journal of Experimental Psychology, 69(3), 574-588. https://doi.org/10.1080/17470218.2015.1062527

Elsner, B., \& Hommel, B. (2001). Effect anticipation and action control. Journal of Experimental Psychology: Human Perception and Performance, 27(1), 229-240. https://doi.org/10.1037//0096-1523.27.1.229

Estes, W. K. (1943). Discriminative conditioning. I. A discriminative property of conditioned 
anticipation. Journal of Experimental Psychology, 32(2), 150-155.

https://doi.org/http://dx.doi.org/10.1037/h0058316

Flach, R., Osman, M., Dickinson, A., \& Heyes, C. (2006). The interaction between response effects during the acquisition of response priming. Acta Psychologica, 122(1), 11-26. https://doi.org/10.1016/j.actpsy.2005.09.001

Hardy, L., Mitchell, C. J., Seabrooke, T., \& Hogarth, L. (2017). Drug cue reactivity involves hierarchical instrumental learning: Evidence from a biconditional Pavlovian to instrumental transfer task. Psychopharmacology, 234(13), 1977-1984. https://doi.org/10.1007/s0021

Hogarth, L. (2012). Goal-directed and transfer-cue-elicited drug-seeking are dissociated by pharmacotherapy: Evidence for independent additive controllers. Journal of Experimental Psychology: Animal Behavior Processes, 38(3), 266-278. https://doi.org/10.1037/a0028914

Hogarth, L., Balleine, B. W., Corbit, L. H., \& Killcross, S. (2013). Associative learning mechanisms underpinning the transition from recreational drug use to addiction. Annals of the New York Academy of Sciences, 1282(1), 12-24. https://doi.org/10.1111/j.1749-6632.2012.06768.x

Hogarth, L., \& Chase, H. W. (2011). Parallel goal-directed and habitual control of human drug-seeking: Implications for dependence vulnerability. Journal of Experimental Psychology: Animal Behavior Processes, 37(3), 261-276. https://doi.org/10.1037/a0022913

Hogarth, L., Dickinson, A., \& Duka, T. (2010). The associative basis of cue-elicited drug taking in humans. Psychopharmacology, 208(3), 337-351. https://doi.org/10.1007/s00213-009-1735-9

Hogarth, L., Dickinson, A., Wright, A., Kouvaraki, M., \& Duka, T. (2007). The role of drug expectancy in the control of human drug seeking. Journal of Experimental Psychology: Animal Behavior Processes, 33(4), 484-496. https://doi.org/10.1037/0097-7403.33.4.484

Hogarth, L., Retzler, C., Munafò, M. R., Tran, D. M. D., Troisi, J. R., Rose, A. K., ... Field, M. (2014). 
Extinction of cue-evoked drug-seeking relies on degrading hierarchical instrumental expectancies. Behaviour Research and Therapy, 59, 61-70.

https://doi.org/10.1016/j.brat.2014.06.001

Holland, P. C. (2004). Relations between Pavlovian-instrumental transfer and reinforcer devaluation. Journal of Experimental Psychology: Animal Behavior Processes, 30(2), 104-117. https://doi.org/10.1037/0097-7403.30.2.104

Kruse, J. M., Overmier, J. B., Konz, W. A., \& Rokke, E. (1983). Pavlovian conditioned stimulus effects upon instrumental choice behavior are reinforcer specific. Learning and Motivation, 14, 165181. https://doi.org/10.1016/0023-9690(83)90004-8

Le Pelley, M. E., Oakeshott, S. M., \& McLaren, I. P. L. (2005). Blocking and unblocking in human causal learning. Journal of Experimental Psychology. Animal Behavior Processes, 31(1), 56-70. https://doi.org/10.1037/0097-7403.31.1.56

Lovibond, P. F. (1981). Appetitive Pavlovian-instrumental interactions: effects of inter-stimulus interval and baseline reinforcement conditions. The Quarterly Journal of Experimental Psychology. B, Comparative and Physiological Psychology, 33(Pt 4), 257-269. https://doi.org/10.1080/14640748108400811

Lovibond, P. F., Satkunarajah, M., \& Colagiuri, B. (2015). Extinction can reduce the impact of reward cues on reward-seeking behavior. Behavior Therapy, 46(4), 432-438. https://doi.org/10.1016/j.beth.2015.03.005

Martinovic, J., Jones, A., Christiansen, P., Rose, A. K., Hogarth, L., \& Field, M. (2014). Electrophysiological responses to alcohol cues are not associated with Pavlovian-toinstrumental transfer in social drinkers. PLoS ONE, 9(4), e94605. https://doi.org/10.1371/journal.pone.0094605 
McLaren, I. P. L., Forrest, C. L. D., McLaren, R. P., Jones, F. W., Aitken, M. R. F., \& Mackintosh, N. J. (2014). Associations and propositions: The case for a dual-process account of learning in humans. Neurobiology of Learning and Memory, 108, 185-195. https://doi.org/10.1016/j.nlm.2013.09.014

McLaren, I. P. L., McAndrew, A., Angerer, K., McLaren, R., Forrest, C., Bowditch, W. A., ... Verbruggen, F. (2018). Mackintosh lecture: association and cognition: two processes, one system. Quarterly Journal of Experimental Psychology. https://doi.org/10.1177/1747021818766287

Mitchell, C. J., De Houwer, J., \& Lovibond, P. F. (2009). The propositional nature of human associative learning. Behavioral and Brain Sciences, 32(2), 183-198.

https://doi.org/10.1017/S0140525X09000855

Moors, A., \& De Houwer, J. (2006). Automaticity: a theoretical and conceptual analysis. Psychological Bulletin, 132(2), 297-326. https://doi.org/10.1037/0033-2909.132.2.297

Pritchard, T. L., Weidemann, G., \& Hogarth, L. (2017). Negative emotional appraisal selectively disrupts retrieval of expected outcome values required for goal-directed instrumental choice. Cognition and Emotion. https://doi.org/10.1080/02699931.2017.1359017

Ridley-Siegert, T. L., Crombag, H. S., \& Yeomans, M. R. (2015). Whether or not to eat : A controlled laboratory study of discriminative cueing effects on food intake in humans. Physiology, 152, 347-353. https://doi.org/10.1016/j.physbeh.2015.06.039

Seabrooke, T., Hogarth, L., \& Mitchell, C. J. (2016). The propositional basis of cue-controlled reward seeking. Quarterly Journal of Experimental Psychology, 69(12), 2452-2470. https://doi.org/10.1080/17470218.2015.1115885

Seabrooke, T., Le Pelley, M. E., Hogarth, L., \& Mitchell, C. J. (2017). Evidence of a goal-directed process in human Pavlovian-instrumental transfer. Journal of Experimental Psychology: Animal 
Learning and Cognition, 43(4), 377-387. https://doi.org/10.1037/xan0000147

Talmi, D., Seymour, B., Dayan, P., \& Dolan, R. J. (2008). Human Pavlovian-instrumental transfer. Journal of Neuroscience, 28(2), 360-368. https://doi.org/10.1523/JNEUROSCI.4028-07.2008

Trick, L., Hogarth, L., \& Duka, T. (2011). Prediction and uncertainty in human Pavlovian to instrumental transfer. Journal of Experimental Psychology: Learning, Memory, and Cognition, 37(3), 757-765. https://doi.org/10.1037/a0022310

Tricomi, E., Balleine, B. W., \& O’Doherty, J. P. (2009). A specific role for posterior dorsolateral striatum in human habit learning. European Journal of Neuroscience, 29(11), 2225-2232. https://doi.org/10.1111/j.1460-9568.2009.06796.x.A

van Steenbergen, H., Watson, P., Wiers, R. W., Hommel, B., \& de Wit, S. (2017). Dissociable corticostriatal circuits underlie goal-directed versus cue-elicited habitual food seeking after satiation: Evidence from a multimodal MRI study. European Journal of Neuroscience, 46(2), 1815-1827. https://doi.org/10.1111/ejn.13586

Walker, K. C. (1942). The effect of a discriminative stimulus transferred to a previously unassociated response. Journal of Experimental Psychology, 31(4), 312-321. https://doi.org/10.1037/h0062929

Watson, P., de Wit, S., Hommel, B., \& Wiers, R. W. (2012). Motivational mechanisms and outcome expectancies underlying the approach bias toward addictive substances. Frontiers in Psychology, 3(October), 1-12. https://doi.org/10.3389/fpsyg.2012.00440

Watson, P., van Steenbergen, H., de Wit, S., Wiers, R. W., \& Hommel, B. (2015). Limits of ideomotor action-outcome acquisition. Brain Research, 1626, 1-9.

https://doi.org/10.1016/j.brainres.2015.02.020

Watson, P., Wiers, R. W., Hommel, B., \& de Wit, S. (2014). Working for food you don't desire. Cues 
interfere with goal-directed food-seeking. Appetite, 79, 139-148.

https://doi.org/10.1016/j.appet.2014.04.005

Watson, P., Wiers, R. W., Hommel, B., Gerdes, V. E. A., \& de Wit, D. (2017). Stimulus control over action for food in obese versus healthy-weight individuals. Frontiers in Psychology, 8. https://doi.org/10.3389/fpsyg.2017.00580

Watson, P., Wiers, R. W., Hommel, B., Ridderinkhof, K. R., \& de Wit, S. (2016). An associative account of how the obesogenic environment biases adolescents' food choices. Appetite, 96, 560-571. https://doi.org/10.1016/j.appet.2015.10.008

Wills, A. J., Graham, S., Koh, Z., McLaren, I. P. L., \& Rolland, M. D. (2011). Effects of concurrent load on feature- and rule-based generalization in human contingency learning. Journal of Experimental Psychology: Animal Behavior Processes, 37(3), 1-5. https://doi.org/10.1007/s13398-014-0173-7.2

Wulfert, E., Maxson, J., \& Jardin, B. (2009). Cue-specific reactivity in experienced gamblers. Psychology of Addictive Behaviors, 23(4), 731-735. https://doi.org/10.1037/a0017134 


\section{Figure Captions}

Figure 1. Results of Experiment 1. (a) Percent choice of the beer (versus chocolate) response during the transfer test in each instruction and load group. (b) Violin plots showing the distribution of percentages (of choice of the beer key) during the transfer test for each instruction and load group. (c) Mean reaction times during the transfer test in each instruction and load group. (d) Mean expectancy ratings for the beer and chocolate in each instruction and load group. Participants rated the extent to which they thought the beer and chocolate stimuli signalled that the associated response was more likely to be rewarded ( $1=$ "Not at all", 7 = "Very much"). Error bars are difference-adjusted 95\% within-subject confidence intervals (Baguley, 2012). (e) The relationship between self-reported expectancy ratings and the size of the transfer effect. Darker symbols represent overlapping data points. The shaded area surrounding the regression line represents the 95\% confidence region.

Figure 2. Transfer test results of Experiment 2 for (a) the entire sample and (b) the sample that demonstrated perfect contingency knowledge. Instrumental response choice was tested in extinction in the presence of two stimulus compounds $(\mathrm{S} 1+\mathrm{S} 3$ and $\mathrm{S} 2+\mathrm{S} 3$ ), under either minimal (No Load) or considerable (Load) cognitive load. Error bars are difference-adjusted 95\% within-subject confidence intervals (Baguley, 2012). 


\section{Table 1}

Design of Experiment 2

\begin{tabular}{|c|c|c|}
\hline Instrumental training & Outcome devaluation & Transfer test \\
\hline $\mathrm{R} 1-01, \mathrm{O}$ & $\mathrm{O} 1$ and $\mathrm{O} 2$ devalued & $\mathrm{S} 1+\mathrm{S} 3: \mathrm{R} 1$ vs $\mathrm{R} 2 ?$ \\
\hline $\mathrm{R} 2-\mathrm{O} 2, \mathrm{O} 3$ & & $\mathrm{~S} 2+\mathrm{S} 3: \mathrm{R} 1$ vs $\mathrm{R} 2 ?$ \\
\hline \multicolumn{3}{|c|}{$\begin{array}{l}\text { Note: R1 and R2 represent instrumental responses, } \mathrm{O} 1 \text { to } \mathrm{O} 3 \text { represent food outcomes (crisps, } \\
\text { popcorn and cashew nuts points), and } \mathrm{S} 1 \text { to } \mathrm{S} 3 \text { represent pictorial stimuli depicting } 01-\mathrm{O} 3 \text { in their }\end{array}$} \\
\hline
\end{tabular}


Table 2

Mean liking ratings in Experiment 2

\begin{tabular}{|c|c|c|c|c|}
\hline & \multicolumn{2}{|c|}{ Pre-devaluation } & \multicolumn{2}{|c|}{ Post-devaluation } \\
\hline & 01/02 & O3 & 01/02 & 03 \\
\hline No Load & $4.45(0.20)$ & $4.68(0.29)$ & $1.16(0.06)$ & $6.25(0.21)$ \\
\hline Load & $4.56(0.22)$ & $4.37(0.33)$ & $1.22(0.08)$ & $6.07(0.24)$ \\
\hline
\end{tabular}

Note. Numbers in parentheses denote SEMs. 

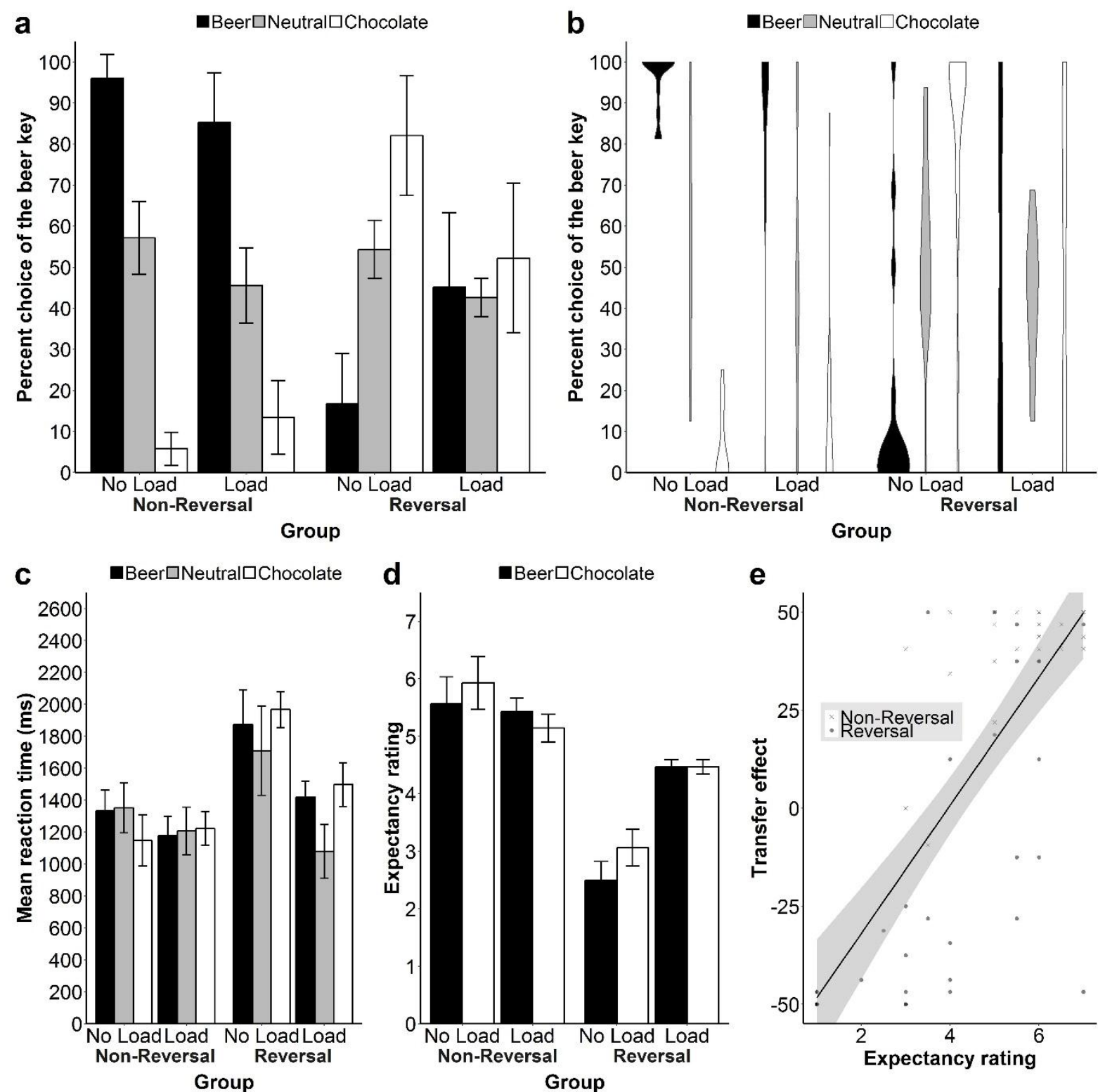

DOI: $10.1177 / 1747021818797052$ 

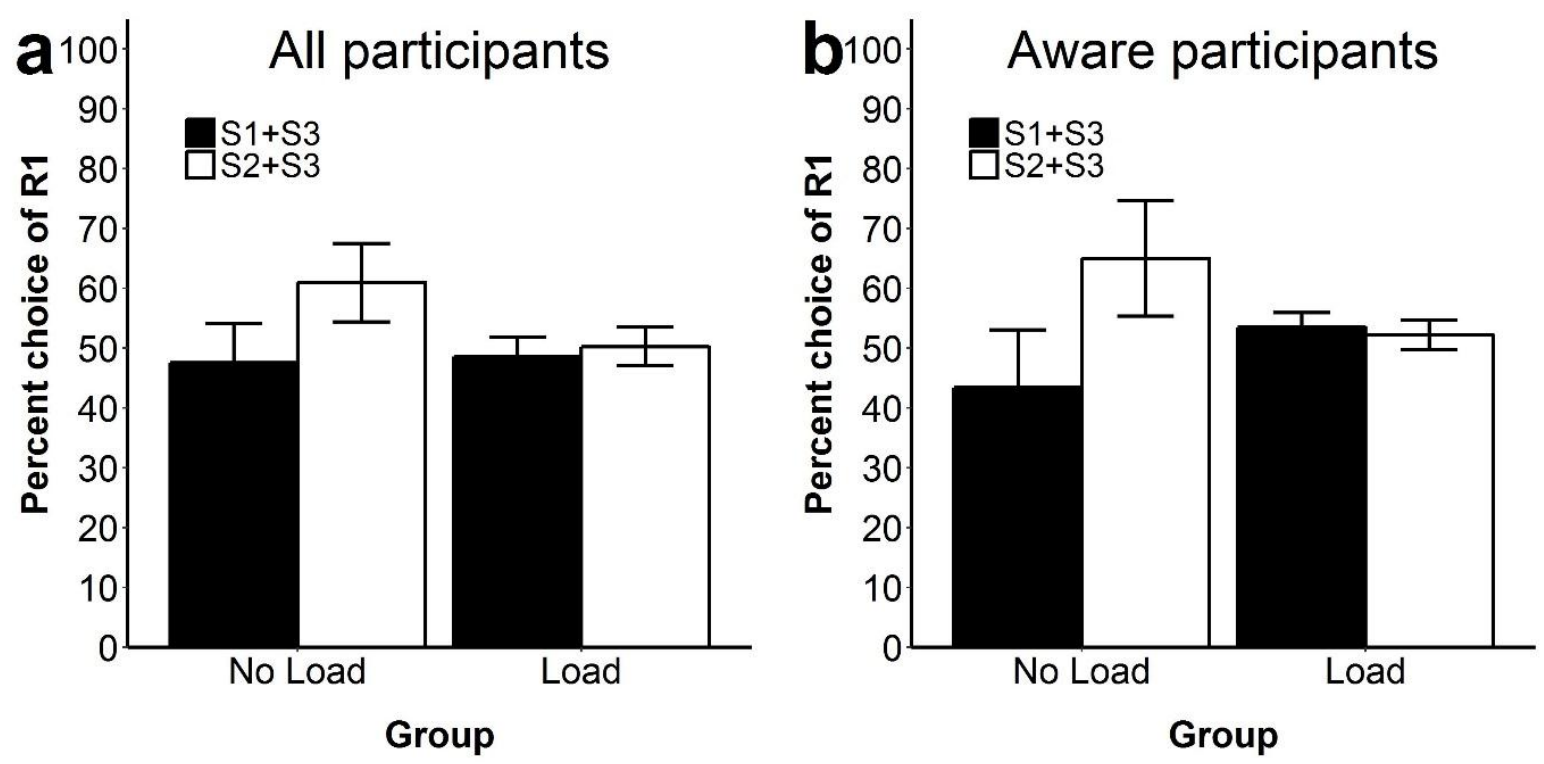

DOI: $10.1177 / 1747021818797052$ 